- Original Paper •

\title{
Different Asian Monsoon Rainfall Responses to Idealized Orography Sensitivity Experiments in the HadGEM3-GA6 and FGOALS-FAMIL Global Climate Models
}

\author{
Kai Chi WONG ${ }^{1}$, Senfeng LIU ${ }^{2,3}$, Andrew G. TURNER ${ }^{* 1}$, and Reinhard K. SCHIEMANN ${ }^{1}$ \\ ${ }^{1}$ Department of Meteorology, University of Reading, Reading RG6 6BB, United Kingdom \\ ${ }^{2}$ State Key Laboratory of Numerical Modeling for Atmospheric Sciences and Geophysical Fluid Dynamics, \\ Institute of Atmospheric Physics, Chinese Academy of Sciences, Beijing 100029, China \\ ${ }^{3}$ University of Chinese Academy of Sciences, Beijing 100049, China
}

(Received 30 October 2017; revised 17 February 2018; accepted 21 March 2018)

\begin{abstract}
Recent work has shown the dominance of the Himalaya in supporting the Indian summer monsoon (ISM), perhaps by surface sensible heating along its southern slope and by mechanical blocking acting to separate moist tropical flow from drier midlatitude air. Previous studies have also shown that Indian summer rainfall is largely unaffected in sensitivity experiments that remove only the Tibetan Plateau. However, given the large biases in simulating the monsoon in CMIP5 models, such results may be model dependent. This study investigates the impact of orographic forcing from the Tibetan Plateau, Himalaya and Iranian Plateau on the ISM and East Asian summer monsoon (EASM) in the UK Met Office's HadGEM3-GA6 and China's Institute of Atmospheric Physics FGOALS-FAMIL global climate models. The models chosen feature oppositesigned biases in their simulation of the ISM rainfall and circulation climatology.

The changes to ISM and EASM circulation across the sensitivity experiments are similar in both models and consistent with previous studies. However, considerable differences exist in the rainfall responses over India and China, and in the detailed aspects such as onset and retreat dates. In particular, the models show opposing changes in Indian monsoon rainfall when the Himalaya and Tibetan Plateau orography are removed. Our results show that a multi-model approach, as suggested in the forthcoming Global Monsoon Model Intercomparison Project (GMMIP) associated with CMIP6, is needed to clarify the impact of orographic forcing on the Asian monsoon and to fully understand the implications of model systematic error.
\end{abstract}

Key words: Tibetan Plateau, East Asian summer monsoon, Indian summer monsoon, model bias, Global Monsoon Model Intercomparison Project (GMMIP)

Citation: Wong, K. C., S. F. Liu, A. G. Turner, and R. K. Schiemann, 2018: Different Asian monsoon rainfall responses to idealized orography sensitivity experiments in the HadGEM3-GA6 and FGOALS-FAMIL global climate models. Adv. Atmos. Sci., 35(8), 1049-1062, https://doi.org/10.1007/s00376-018-7269-5.

\section{Introduction}

The Asian summer monsoon is a significant component of the Asian climate system. The summer rainfall brought by its two sub-systems, the Indian summer monsoon (ISM) and the East Asian summer monsoon (EASM), supports economic activity in rapidly developing economies within the monsoon region, such as India and China. Since the Asian summer monsoon is fundamentally driven by the land-sea thermal contrast between the Eurasian landmass and adjacent water bodies such as the Indian and Pacific oceans in summer, a lot of research in recent decades has focused on the impact of surface sensible heating in maintaining the meridional

\footnotetext{
* Corresponding author: Andrew G. TURNER

Email: a.g.turner@ reading.ac.uk
}

temperature gradient that drives the cross-equatorial overturning circulation of the monsoon. For example, $\mathrm{Li}$ and Yanai (1996) suggested the onset of the Asian summer monsoon is closely associated with the reversal of the meridional temperature gradient in May to June, which is a direct result of large-scale temperature increases in the upper-troposphere over Eurasia. More recently, Xavier et al. (2007) showed the onset and retreat of the ISM defined using the mid-toupper tropospheric temperature gradient between the Indian subcontinent and the equatorial Indian Ocean is largely consistent with other rainfall-based monsoon indices.

The Tibetan Plateau (TP) is the world's highest and largest plateau and has long been considered an important component of the Asian summer monsoon (e.g., Flohn, 1957; Ye, 1981). Yanai et al. (1992) also showed that the TP is an effective heat source during summer, and the surface sensible 
heating emanating from its elevated surface is crucial in reversing the meridional temperature gradient leading to monsoon onset. Wu et al. (2007) also argued that the strong sensible heating from the plateau's surface in summer produces ascending motion and surface convergence, while in winter air descends and diverges from the plateau such that the shift in circulation regime between summer and winter is similar to a sensible-heat-driven "air pump".

However, recent studies (e.g., Wu et al., 2012; Boos and Kuang, 2013) have shown that, in climate model simulations, the ISM is more sensitive to the surface heating emanating from the southern slopes of the Himalaya and the relatively low-lying northern Indian subcontinent, while elevated heating from the plateau's surface is not necessarily required to maintain the ISM. Ma et al. (2014) also showed that the strength of the ISM decreases approximately linearly as the height of the Himalaya is reduced in a climate model, suggesting that mechanical blocking by the Himalaya of drier and cooler midlatitude air may also be crucial in supporting the ISM (Boos and Kuang, 2010).

Meanwhile, accurate simulation of the Asian summer monsoon remains a grand challenge and CMIP5 climate models are known to have significant biases when simulating the climatology of the Asian monsoons (Kitoh et al., 2013; Dong et al., 2016). For the ISM, the multi-model mean shows a weaker monsoon when compared to reanalysis data, with weakened summer westerlies over the Arabian Sea, India and the Bay of Bengal (e.g., Sperber et al., 2013; Wang et al., 2017). While CMIP5 climate models are able to simulate the overall circulation and precipitation characteristics of the EASM more accurately than the ISM, significant variability also exists in the strength and position of the western Pacific subtropical high and in the intensity and seasonal migration of the mei-yu/changma/baiu rainbelt (e.g., Feng et al., 2014; Song and Zhou, 2014). The diverse biases among climate models also suggest there can be considerable model dependency when investigating the monsoon response to orographic forcing in sensitivity experiments.

Using a different global climate model, the UK Met Office's HadGEM3, Wong et al. ' (hereafter WTS2017) repeated several sensitivity experiments conducted previously in Boos and Kuang $(2010,2013)$. While the response in ISM circulation to orographic forcing was generally consistent with previous studies, their results showed that the response in rainfall can be model dependent. However, it is unclear whether their results can be considered robust given HadGEM3's large bias in simulating the Indian summer rainfall climatology. Contrary to the ISM, WTS2017 also showed that the EASM is more sensitive to the forcing from the TP compared to the Himalaya, but further investigation is needed to determine if the significant rainfall bias in the ISM region affects the transport of moisture toward the South China Sea. Nevertheless, the results in WTS2017 demonstrate the need for a multi-model approach, such as the forthcoming Global Monsoon Model
Intercomparison Project [GMMIP; see Zhou et al. (2016) for a summary], to investigate the complex response of the Asian monsoon to orography.

To investigate to what extent the response of the ISM and EASM to change in orographic forcing is dependent on the choice of climate model, in this study we repeat some of the idealized orography numerical simulations of WTS2017 using two separate climate models. The UK Met Office's HadGEM3 and the Institute of Atmospheric Physics' FGOALS-FAMIL global climate models are chosen because of their different behavior in simulating the climatology of the ISM and EASM.

Details of both models and the experimental setup are provided in section 2. Key results are presented in section 3 , followed by conclusions and discussion in section 4 .

\section{Methods}

\subsection{Summary of HadGEM3}

The UK Met Office's Unified Model, HadGEM3 Global Atmosphere 6.0 (Walters et al., 2017), is used to perform various sensitivity simulations with modified orography. This version of HadGEM3 includes the ENDGame (Even Newer Dynamics for General Atmospheric Modelling of the Environment) dynamical core, which uses a semi-implicit semiLagrangian formulation to solve the non-hydrostatic, fully compressible deep-atmosphere equations of motion. Prognostic variables are discretized horizontally onto a regular longitude-latitude grid with Arakawa C-grid staggering, and vertically onto a terrain-following hybrid height coordinate with Charney-Phillips staggering. The horizontal resolution is set at N96 (roughly $200 \mathrm{~km}$ grid spacing at the equator) and there are 85 vertical levels in the model domain with a fixed top lid at $85 \mathrm{~km}$ above sea level.

\subsection{Summary of FGOALS-FAMIL}

The sensitivity simulations are then repeated using the FGOALS-FAMIL (hereafter FGOALS-f) atmospheric general circulation model (AGCM) developed by the State Key Laboratory of Numerical Modeling for Atmospheric Sciences and Geophysical Fluid Dynamics (LASG), Institute of Atmospheric Physics (IAP), Chinese Academy of Sciences (Zhou et al., 2012, 2015; Yu et al., 2014). Its dynamical core uses a finite-volume algorithm calculated on a cubed-sphere grid system with flexible resolution (Lin, 2004; Putman and Lin, 2007). In the present study, the model resolution is also set at N96, as in HadGEM3. In the vertical direction, there are 32 vertical levels with a top pressure of $2.16 \mathrm{hPa}$.

A comparison of the physical parametrizations incorporated in the two models is provided in Table 1.

\subsection{Experimental setup}

Firstly, a control experiment forced with interannually varying sea surface temperature data according to the AMIP

\footnotetext{
${ }^{a}$ Wong, K. C., A. G. Turner, and R. K. Schiemann, 2017: Differing impacts of Tibetan Plateau and Himalayan region orography on the East and South Asian monsoon. Climate Dyn., in revision.
} 
Table 1. AGCM physical parametrizations.

\begin{tabular}{|c|c|c|}
\hline Physical parameterization & FGOALS-f & HadGEM3 \\
\hline Cumulus convection & $\begin{array}{l}\text { A mass flux cumulus parameterization (Tiedtke, } \\
\text { 1989), adding a variant based on convective avail- } \\
\text { able potential energy (Nordeng, 1994) }\end{array}$ & $\begin{array}{l}\text { A mass flux convection scheme based on Gregory and } \\
\text { Rowntree (1990) with a convective available poten- } \\
\text { tial energy closure based on Fritsch and Chappell } \\
\text { (1980) }\end{array}$ \\
\hline Cloud microphysics & $\begin{array}{l}\text { A single-moment cloud microphysics scheme (Harris } \\
\text { and Lin, 2014) }\end{array}$ & $\begin{array}{l}\text { Prognostic cloud fraction and prognostic condensate } \\
\text { (PC2) scheme (Wilson et al., 2008a, 2008b) }\end{array}$ \\
\hline Planetary boundary layer & $\begin{array}{l}\text { A non-local first-order closure scheme (Holtslag and } \\
\text { Boville, 1993) }\end{array}$ & $\begin{array}{l}\text { First order turbulence closure scheme (Lock et al., } \\
\text { 2000) }\end{array}$ \\
\hline Gravity wave drag & Only orographic gravity waves (Palmer et al., 1986) & $\begin{array}{l}\text { Effective roughness parametrization (Wood and Ma- } \\
\text { son, 1993) for sub-grid orographic drag, spec- } \\
\text { tral sub-grid parametrization scheme (Scaife et al., } \\
\text { 2002) for non-orographic gravity-wave drag }\end{array}$ \\
\hline Radiative transfer & $\begin{array}{l}\text { Rapid Radiative Transfer Model for GCMs (RRTMG) } \\
\text { (Clough et al., 2005) }\end{array}$ & Radiation scheme of Edwards and Slingo (1996) \\
\hline
\end{tabular}

protocol (Gates et al., 1998) is conducted using both models. Four sensitivity experiments with modified orography, designed to isolate the orographic forcing from the TP, Himalaya and Iranian Plateau (IP), are then performed. In each sensitivity experiment, the targeted orography is lowered to $500 \mathrm{~m}$ above sea level to remove the mechanical blocking and to lower the elevation of surface heating. Table 2 lists the experiments performed and regional bounds of the orographic adjustment, while Fig. 1 shows the orography used in each experiment.

All experiments in HadGEM3 are initialized using reanalysis data on 1 September 1981 and integrated forward in time for 20 years until 30 August 2001. For FGOALS-f, the experiments are initialized with a zero-value state such that they begin earlier, at 1978, and are integrated until 2001, with the first three years being discarded for model spin-up. For consistency, the monsoon climatology from both models is defined using the 20-year average from September 1981 to August 2001, which includes 20 summer (June-August) periods.

\subsection{Observational data}

For precipitation, the model results are compared to data from version 2.2 of the Global Precipitation Climatology Project (GPCP) Monthly Precipitation Analysis dataset (Adler et al., 2003). This dataset is a merged analysis that includes estimates from low-orbit satellite microwave data, geostationary satellite infrared data and surface rain gauge

Table 2. List of sensitivity experiments. $\sqrt{ }$ denotes terrain unchanged and $\times$ denotes terrain lowered to $500 \mathrm{~m}$ above sea level.

\begin{tabular}{lccc}
\hline Name of experiment & TP & Himalaya & IP \\
\hline CON & $\sqrt{ }$ & $\sqrt{ }$ & $\sqrt{ }$ \\
NoTP & $\times$ & $\times$ & $\sqrt{ }$ \\
HM-IPonly & $\times$ & $\sqrt{ }$ & $\sqrt{ }$ \\
NoIP & $\sqrt{ }$ & $\sqrt{ }$ & $\times$ \\
HMonly & $\times$ & $\sqrt{ }$ & $\times$ \\
\hline
\end{tabular}

observations, at $2.5^{\circ} \times 2.5^{\circ}$ resolution. The data between 1981 and 2001 are used to produce the summer precipitation climatology, which is then interpolated to the N96 resolution for comparison with both models. For fields such as wind, temperature and moisture at various pressure levels and for column-integrated moisture flux, the ERA-Interim atmospheric reanalysis dataset (Dee et al., 2011) is used. Reference data from ERA-Interim are produced by averaging over the period 1981-2001 and then interpolated from the original $0.7^{\circ} \times 0.7^{\circ}$ resolution to the $\mathrm{N} 96$ resolution for comparison.

\section{Results}

\subsection{Control experiment and model bias}

Before analyzing the impacts of orographic forcing on the South and East Asian monsoons in the HadGEM3 and FGOALS-f models, we first compare their mean-state simulation against observational data. Figures $2 \mathrm{a}$ and $\mathrm{b}$ show the summer (June-August) average rainfall and $850 \mathrm{hPa}$ circulation from the control experiment (hereafter referred to as CON) in FGOALS-f and HadGEM3. Both models are able to simulate the large-scale features of the westerly summer monsoon flow over India and the Bay of Bengal, as well as the southerly summer monsoon into southern China. However, the models feature contrasting biases in summer rainfall and $850 \mathrm{hPa}$ circulation patterns when compared to observed estimates. For FGOALS-f (Fig. 2c), there is a strong ISM bias with a meridionally narrow core of enhanced westerlies passing from the Arabian Sea over the southern peninsular India. This is associated with a cyclonic anomaly to the north, representing an enhancement of the monsoon trough, and an anticyclonic circulation anomaly to the south. Anomalous horizontal convergence leads to a positive rainfall bias to the southwest of India, while the eastern Arabian Sea and western Bay of Bengal receive 4-8 $\mathrm{mm} \mathrm{d}^{-1}$ more rainfall than observed estimates, consistent with the strong circulation. Compared to the ISM, the EASM is more accurately simulated in FGOALS-f, with little circulation bias over China; although, 
(a) Con

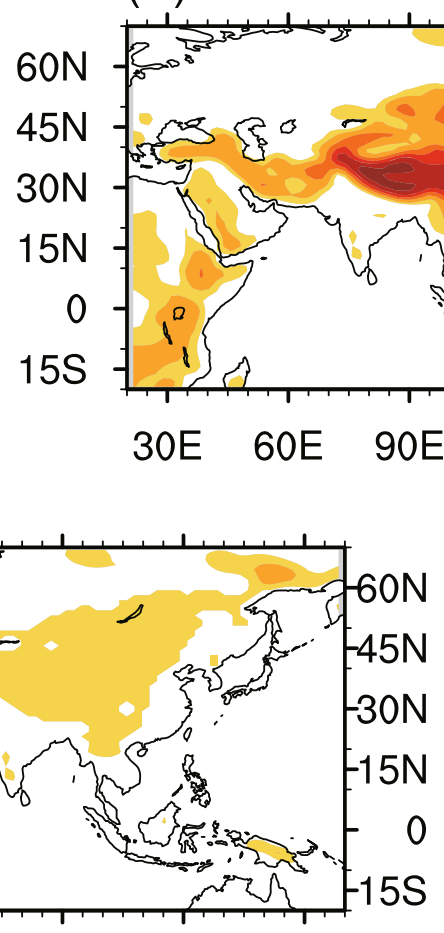

$15 S$

(b) NoTP

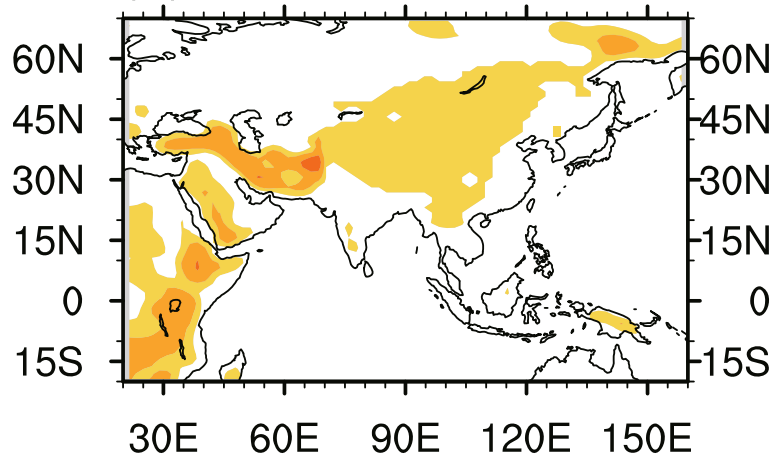

(d) NolP

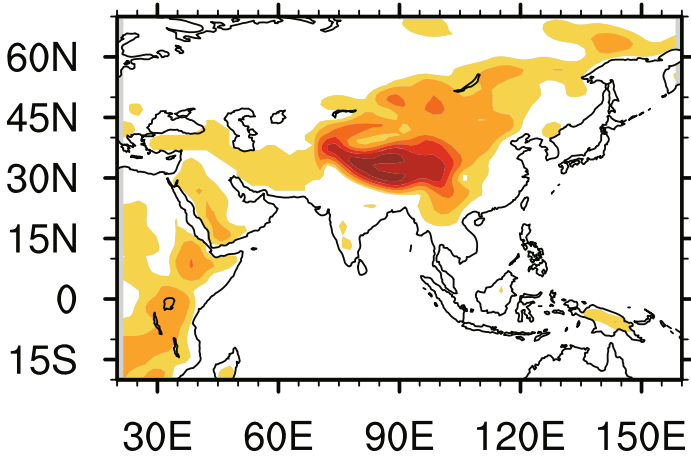

Height (m)

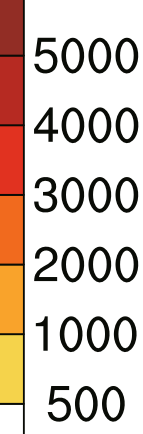

(c) HM-IPonly

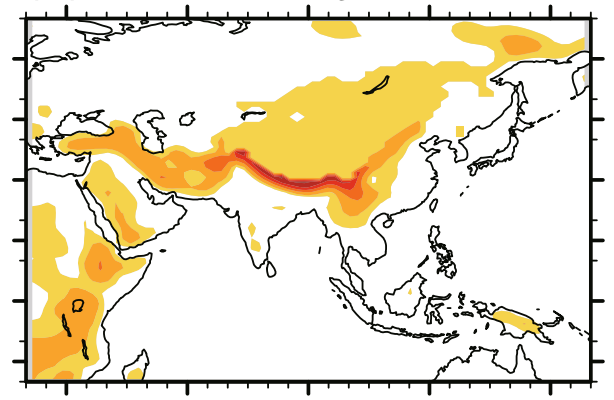

30E 60E 90E 120E 150E

(e) HMonly

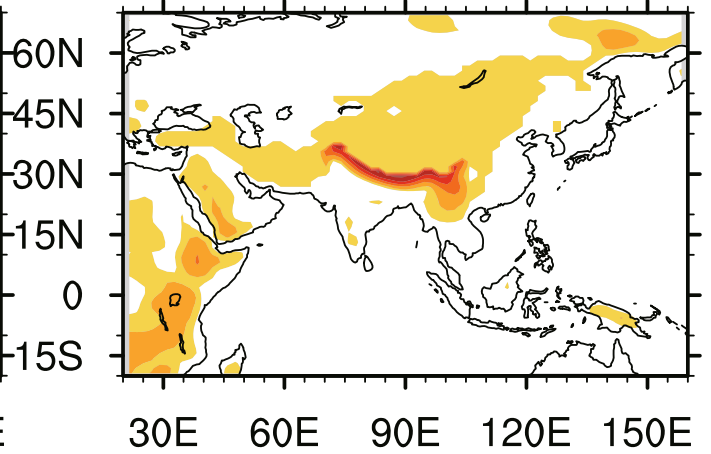

Fig. 1. Orography data used in (a) CON, (b) NoTP, (c) HM-IPonly, (d) NoIP and (e) HMonly.

easterly anomalies can be found over the western Pacific, related to biases in the strength or mean position of the subtropical high. Biases in summer rainfall over China are also small compared to those in the ISM region, but these could be caused by the EASM's smaller summer mean rainfall compared to the ISM.

Contrary to FGOALS-f's strong ISM bias, HadGEM3's CON shows a weak ISM bias (Fig. 2d). The summer lowertropospheric westerlies over the Arabian Sea are weak compared to observed estimates, while most of India and the Bay of Bengal receives 6-10 $\mathrm{mm} \mathrm{d}^{-1}$ less summer rainfall than observed estimates. A significant wet bias (of more than 10 $\mathrm{mm} \mathrm{d}^{-1}$ ) is found over the equatorial Indian Ocean, which is a common bias among models, as discussed previously in
Sperber et al. (2013) and Bollasina and Ming (2013). The coupling between deficient ISM rainfall and a weakened circulation is clear among the CMIP5 multi-model ensemble (Sperber et al., 2013). Similar to FGOALS-f, the EASM in HadGEM3's CON is also better simulated than the ISM. There is little rainfall or circulation bias over China; although, a cyclonic anomaly can be found over the western Pacific, indicating a weaker subtropical high relative to observed estimates. Overall, the weak ISM bias in HadGEM3 is more like the CMIP3 or CMIP5 multi-model mean shown in Sperber et al. (2013). The fact that the two models chosen here exhibit biases of opposite sign over the Indian monsoon region is desirable, since it will allow us to determine the robustness of the modeled monsoon response to orography and present 

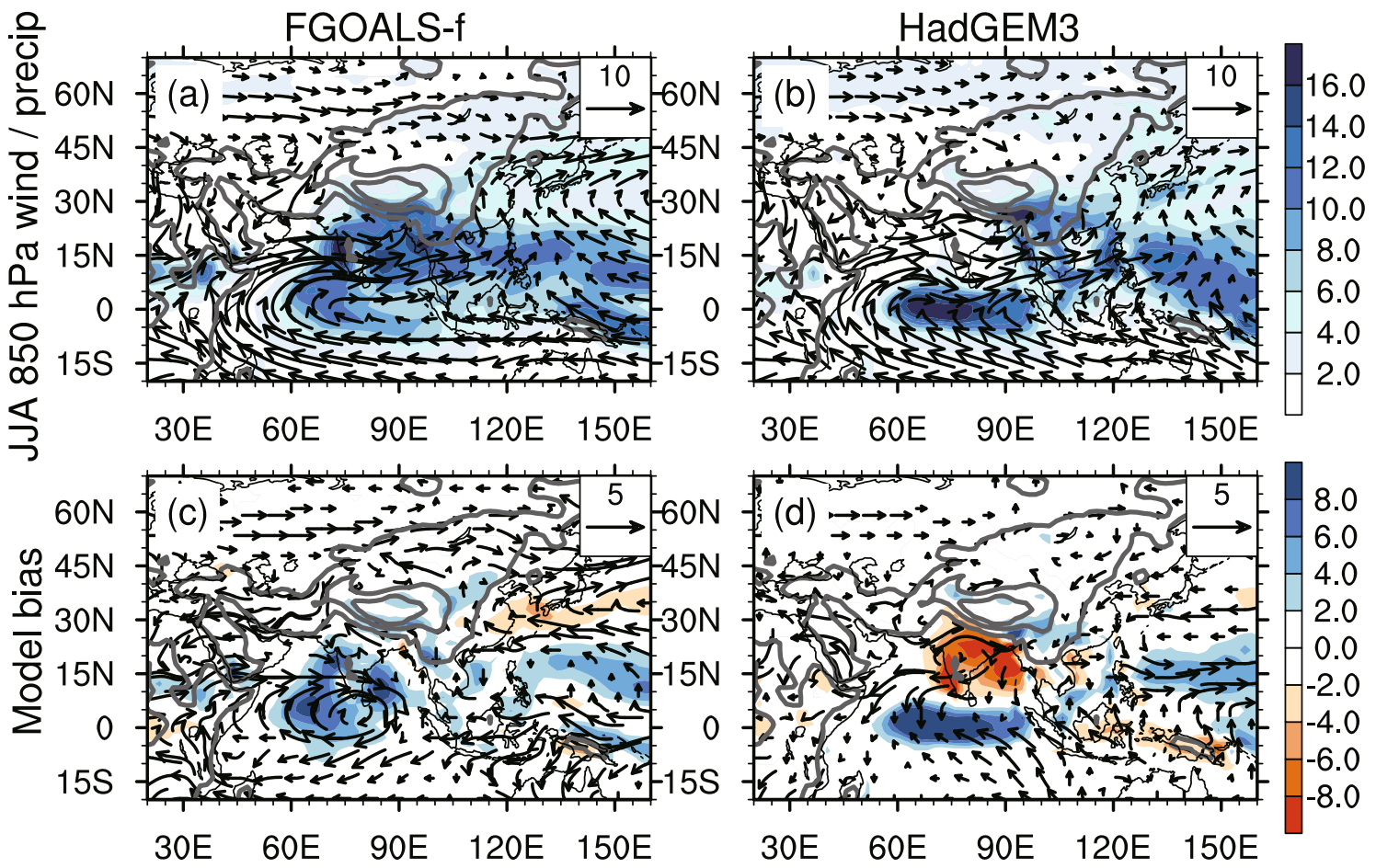

Fig. 2. Summer (June-August) average precipitation (shading; units: $\mathrm{mm} \mathrm{d}^{-1}$ ) and $850 \mathrm{hPa}$ wind (vectors; units: $\mathrm{m}$ $\mathrm{s}^{-1}$ ) over the period 1981-2001 from the CON experiment of (a) FGOALS-f and (b) HadGEM3, and (c, d) their bias compared to GPCP and ERA-Interim data. Grey lines denote coastline and elevation contours from $500 \mathrm{~m}$ at $2000 \mathrm{~m}$ intervals.

some insight into the impact of monsoon biases.

\subsection{Sensitivity experiments: changes in rainfall and cir- culation}

Four sensitivity experiments targeting the orographic forcing from the TP, Himalaya and the IP are performed in both models. The 20-year average of summer rainfall and $850 \mathrm{hPa}$ circulation from the sensitivity experiments are then compared to the corresponding CON experiment, thus demonstrating the impact of orographic forcing from the targeted terrain on the monsoon.

In the "no TP" (NoTP) experiment, all terrain inside $\left(20^{\circ}-60^{\circ} \mathrm{N}, 70^{\circ}-150^{\circ} \mathrm{E}\right)$ is lowered to $500 \mathrm{~m}$ above sea level, thus removing the orographic forcing from both the TP and the Himalaya. Both models show a similar response in 850 $\mathrm{hPa}$ circulation, but the change in summer rainfall is different (Figs. 3a and b). In the ISM region, a weakened monsoon circulation is found with easterly anomalies over India and the Arabian Sea. The EASM also reduces in strength, with northeasterly anomalies dominating southern China and the South China Sea, representing a weakened penetration of the monsoon winds into East Asia.

For summer rainfall, FGOALS-f shows a clear reduction in the ISM region relative to $\mathrm{CON}$, particularly over northern India and along the southern edge of the TP; however, there is little change in the EASM region over China. In contrast, and despite the weakened large-scale monsoon circulation, HadGEM3 shows increased rainfall over southern India and the Bay of Bengal; although, reduced rainfall is found over the southeastern TP and most of China. The reduced rainfall under a weakened ISM in FGOALS-f is more consistent with the results presented in previous studies and could be considered more robust than the results from HadGEM3 given its smaller rainfall bias in CON. Examination of the change in circulation over India suggests subtle differences in the location of convergence zones between the models may give rise to the precipitation differences there; this will be analyzed later in section 3.3. Further investigation is also needed to explain the different responses in rainfall over China, since the EASM in the CON of both models is accurately simulated, with little bias in summer rainfall over China.

A "Himalaya and IP-only" (HM-IPonly) experiment is then conducted to demonstrate the value of orographic forcing provided by the Himalaya and IP. The orography used in HM-IPonly is the same as in NoTP, except that the Himalaya are retained to form a roughly zonal barrier separating moist air over the Indian subcontinent from presumably drier air over the Eurasian landmass. The response in 850 $\mathrm{hPa}$ circulation is again very consistent between FGOALS-f and HadGEM3 (Figs. 3c and d). Both models show reduced easterly anomalies over India and the Arabian Sea compared to NoTP, as well as much weaker circulation anomalies over China. The response in summer rainfall is still different, with FGOALS-f showing little change over India relative to CON, except a small 2-4 $\mathrm{mm} \mathrm{d}^{-1}$ reduction along the southern edge of the TP. For HadGEM3, increased rainfall is still found over northeastern India and the Bay of Bengal relative to CON, but the change is much smaller compared to that in NoTP. 

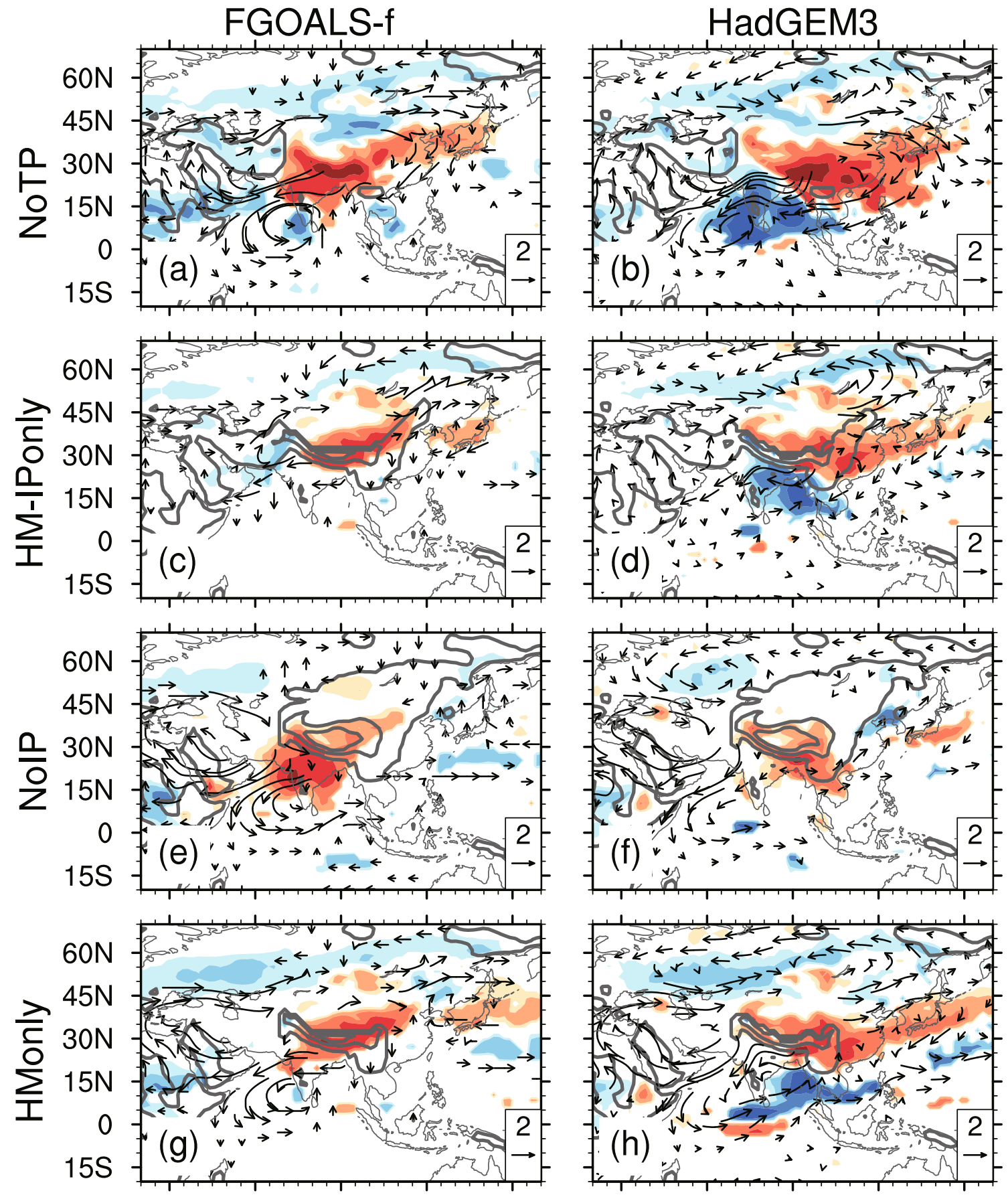

\begin{tabular}{llllllllllll}
$30 \mathrm{E}$ & $60 \mathrm{E}$ & $90 \mathrm{E}$ & $120 \mathrm{E}$ & $150 \mathrm{E}$ & \multicolumn{2}{l}{$30 \mathrm{E}$} & $60 \mathrm{E}$ & $90 \mathrm{E}$ & $120 \mathrm{E}$ & $150 \mathrm{E}$ \\
-8.0 & -4.0 & -2.0 & -1.0 & -0.5 & 0.0 & 0.5 & 1.0 & 2.0 & 4.0 & 8.0
\end{tabular}

Fig. 3. Difference in summer average precipitation (shading; units: $\mathrm{mm} \mathrm{d}^{-1}$ ) and $850 \mathrm{hPa}$ wind (vectors; units: $\mathrm{m} \mathrm{s}^{-1}$ ) between ( $\mathrm{a}, \mathrm{b})$ NoTP, (c, d) HM-IPonly, (e, f) NoIP and (g, h) HMonly, relative to CON, for FGOALS-f (left) and HadGEM3 (right). Only signals passing the $95 \%$ confidence level are plotted. Grey lines denote coastline and elevation contours above $500 \mathrm{~m}$ at $2000 \mathrm{~m}$ intervals.

Despite the different response in rainfall over the ISM region between the two models, the reduced circulation and rainfall anomaly compared to the respective NoTP experiment suggests the ISM in this experiment is more similar to that in CON. This demonstrates the crucial role played by the Himalaya in maintaining the ISM and is consistent with previous studies. Over the EASM region, both models again disagree on the change in summer rainfall over China, with no change at all in FGOALS-f but a $2-4 \mathrm{~mm} \mathrm{~d}^{-1}$ reduction in HadGEM3. Such results show that the EASM in HadGEM3 
is sensitive to the forcing from the TP and that orographic forcing from the Himalaya alone is insufficient to maintain the summer rainfall over China, while FGOALS-f is unable to demonstrate a similar connection between the EASM and TP. This will be further investigated later using other diagnostics to examine the downstream response over East Asia.

A "no IP" (NoIP) experiment is performed to investigate the impact of orographic forcing provided by the IP, since it is located directly upstream of the Indian subcontinent with respect to the summer midlatitude westerlies. The orography used in this experiment is identical to that in CON, except that the IP is lowered from its typical height of $1000 \mathrm{~m}$ to $500 \mathrm{~m}$ above sea level. Both models show a consistent response in $850 \mathrm{hPa}$ circulation. An anticyclonic circulation anomaly is found centered over the IP with its southeastern quadrant covering the northern Arabian Sea, resulting in extensive easterly anomalies to the west of India (Figs. 3e and f). This anticyclonic anomaly could be interpreted both as a response to removal of surface heating and as a direct impact of unblocking the Hindu Kush region west of the Himalaya. While the Arabian Sea easterly anomalies found in both models are likely to reduce the moisture transport from the Arabian Sea toward India, only in FGOALS-f does the circulation penetrate over India enough to enable a 4-8 $\mathrm{mm}$ $\mathrm{d}^{-1}$ reduction in rainfall over most of India. In HadGEM3, summer rainfall over India is the same as in CON, although a 4-6 $\mathrm{mm} \mathrm{d}^{-1}$ reduction in rainfall is found further downstream over northern Indochina. Both models show little change in the EASM rainfall, but FGOALS-f features stronger westerlies over the South China Sea.

Given the significant impact of the IP on the ISM demonstrated in NoIP, a further "Himalaya-only" (HMonly) experiment is conducted to isolate the orographic forcing from the Himalaya. The orography used is identical to that in HMIPonly, except the IP is also lowered. The results from both models are largely similar to those from NoIP, characterized by an anticyclonic circulation anomaly over the IP region and northeasterly anomalies over the Arabian Sea (Figs. 3g and h).

The above results demonstrate the considerable model dependency when investigating the impact of orographic forcing on the monsoonal rainfall using global climate model experiments. For the ISM, the results from FGOALS-f are more consistent with previous studies, with reduced summer rainfall over India without the orographic forcing provided by the Himalaya and IP. The different response between NoIP and HMonly in FGOALS-f is unexpected, since both experiments lack the IP; this will be further investigated in the next section using moisture flux diagnostics. HadGEM3, however, shows different results, with increased Indian rainfall when the Himalaya and TP are removed from the model in NoTP, most likely related to the model's inability to accurately simulate the ISM rainfall climatology in CON. Nevertheless, the response in $850 \mathrm{hPa}$ circulation across the experiments is largely consistent between both models and is supportive of the consensus that the ISM is not sensitive to the elevation of surface heating emanating from the TP's sur- face. Both models also show different results for the EASM, as the link between the TP and summer rainfall over China is captured only in HadGEM3 but not in FGOALS-f.

\subsection{Sensitivity experiments: changes in moisture flux and its convergence}

The responses in rainfall can be largely explained by changes in moisture flux and its convergence associated with the ISM and EASM. For NoTP (Figs. 4a and b), the reduction in summer rainfall over India is consistent with reduced moisture convergence there relative to $\mathrm{CON}$. The results from HadGEM3 are different, with enhanced moisture convergence over India and the Bay of Bengal, thus explaining the enhanced rainfall relative to $\mathrm{CON}$. This implies that the winds over India are slowed more rapidly than those over the Arabian Sea. The reduction in moisture convergence over the southern TP in HadGEM3 is similar to that in FGOALS-f but covers a larger area, extending further eastward into China and the West Pacific. Both models show similar changes in column-integrated moisture flux, with easterly anomalies dominating the northern Arabian Sea and northeasterly anomalies in the EASM domain, similar to the responses in $850 \mathrm{hPa}$ circulation.

In HM-IPonly, the changes in moisture flux and convergence in FGOALS-f are much smaller when compared to those in NoTP, suggesting that the Himalaya dominate the orographic control of the monsoonal circulation. For HadGEM3 the increased moisture convergence along the west coast of India previously found in NoTP has reduced, but stronger convergence relative to $\mathrm{CON}$ is still found over the Bay of Bengal. Similar to the changes in summer rainfall, only HadGEM3 is able to show reduced moisture convergence over southern China in HM-IPonly.

In NoIP, FGOALS-f shows a clear reduction in moisture convergence over northern India and reduced westerly moisture flux toward India from the Arabian Sea. Although HadGEM3 also shows a similar reduction in westerly moisture flux toward India, removing the IP has little impact on the moisture convergence over India. Results from HMonly are also consistent with the responses in summer rainfall, with FGOALS-f showing the impact of the IP on moisture convergence over India and HadGEM3 demonstrating the clear impact of the TP on moisture convergence over China.

For a more quantitative comparison of the strength of the ISM and EASM between both models, Fig. 5 shows the cumulative moisture flux profiles computed at two locations, after the method developed in WTS2017. Given the dominant directions of the mean monsoonal circulation, for the ISM (Figs. 5a and b), the zonal component of the columnintegrated moisture flux (westerly flux only) is accumulated along the $0^{\circ}-25^{\circ} \mathrm{N}$ meridional line at $65^{\circ} \mathrm{E}$ to demonstrate the strength of the westerly summer monsoon. For the EASM (Figs. 5c and d), the meridional moisture flux (southerly flux only) accumulated crossing the zonal $110^{\circ}-130^{\circ} \mathrm{E}$ line at $25^{\circ} \mathrm{N}$ over the South China Sea is used. Each model's bias in simulating the ISM can be clearly seen when comparing the cumulative moisture flux profile from $\mathrm{CON}$ to observed es- 


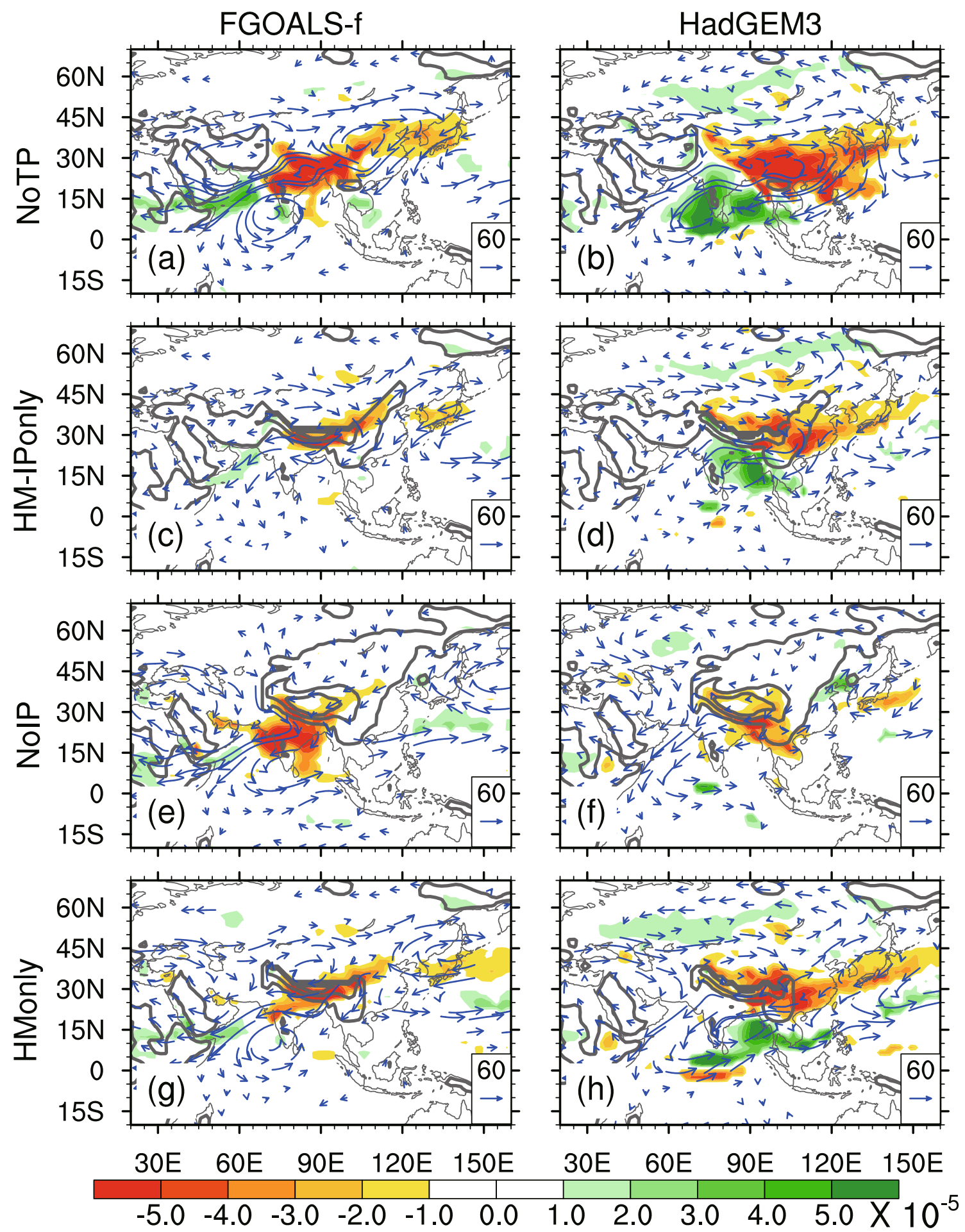

Fig. 4. As in Fig. 3 but for column-integrated moisture flux (vectors; units: $\mathrm{kg} \mathrm{m}^{-1} \mathrm{~s}^{-1}$ ) and moisture convergence (shading; units: $\mathrm{kg} \mathrm{m}^{-2} \mathrm{~s}^{-1}$ ).

timates derived from ERA-Interim. In FGOALS-f, although the monsoon onset occurs in early May in CON, just as in the reanalysis, the moisture flux increases more rapidly during the model's monsoon season leading to a $51 \%$ overestimate in the annual total. On the contrary, HadGEM3's weak ISM circulation bias results in a weaker moisture flux that persists throughout the monsoon season, with a $32 \%$ decrease in the annual total relative to observed estimates. From a moisture flux perspective, therefore, the mean-state bias in the FGOALS model is larger than that of HadGEM3.

Despite the opposite model biases leading to large differences in the annual total accumulated moisture flux, the changes in westerly moisture flux toward India in the sensitivity experiments are very consistent between the mod- 

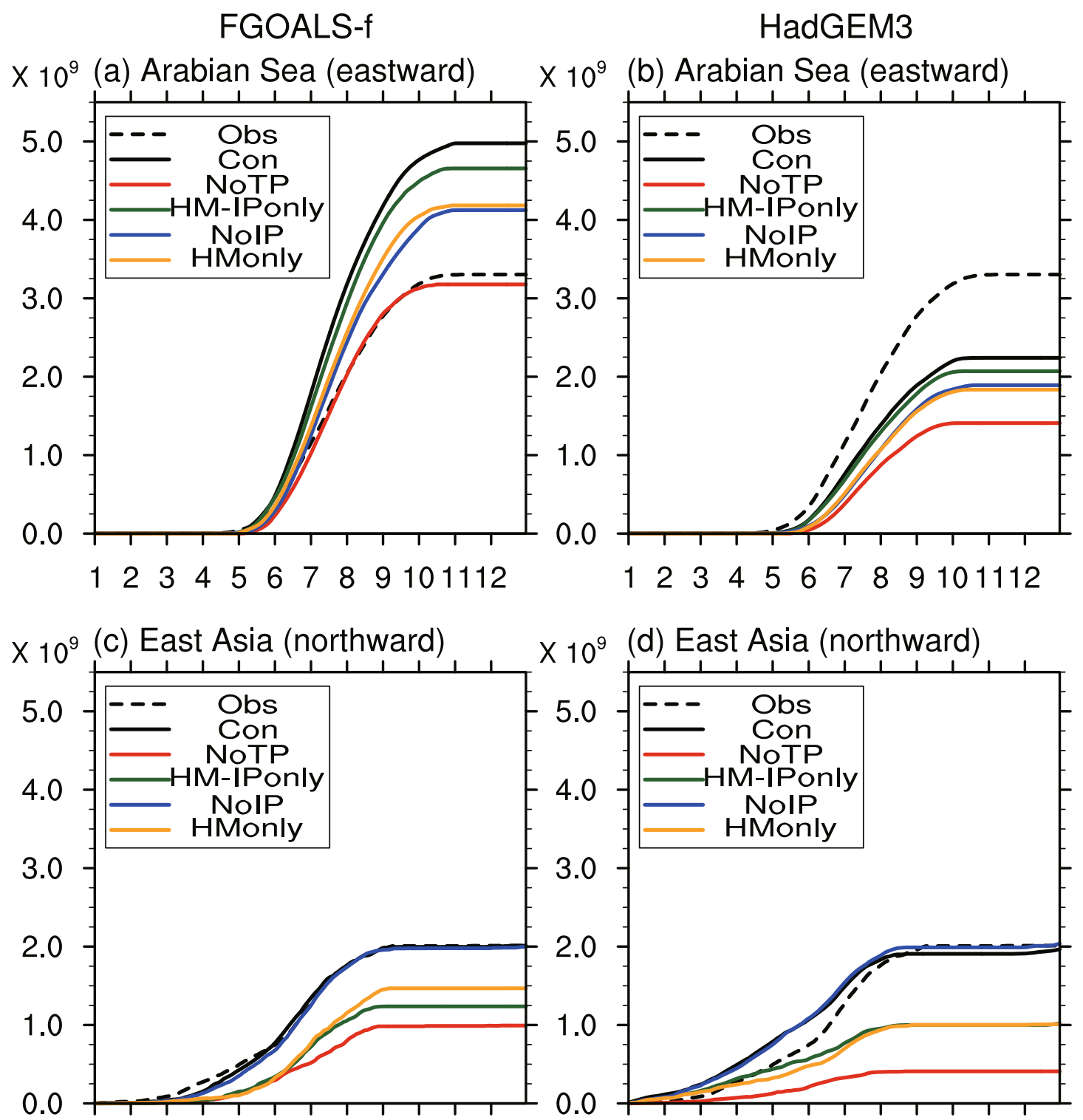

1223445667889101112

1223445667889101112

Fig. 5. Cumulative moisture flux (vertical axis; units: $\mathrm{kg} \mathrm{m}^{-1}$ ) over the (a, b) Arabian Sea (westerly component only) and (c, d) South China Sea (southerly component only) in observed estimates and all experiments of (a, c) FGOALS-f and $(b, d)$ HadGEM3.

els. In NoTP, both models show weakened westerly moisture flux during summer and the largest reduction in annual total among all experiments $(36 \%$ in FGOALS-f, $38 \%$ in HadGEM3). With the Himalaya retained in HM-IPonly, both models show significant improvement relative to NoTP during the monsoon season, as the annual total is more consistent to CON with only a small reduction (6\% in FGOALS-f, $9 \%$ in HadGEM3). While the changes in rainfall in NoIP and HMonly are different between both models, a more consistent response is found in the moisture flux. Without the IP, both models show reduced westerly moisture flux during summer, as well as a reduced annual total, in NoIP and HMonly ( $-16 \%$ to $-20 \%$ for both experiments), demonstrating the impact of the IP on the moisture transport by the ISM. This reduced flow of moisture toward India is consistent with an anomalous influx of low moist static energy air (not shown) emanating from the northwest over the IP region.

For the EASM, both models are quite accurate at simulating the southerly moisture flux from the South China Sea toward China, showing realistic annual totals in CON when compared to observed estimates. However, in a separate analysis focusing on the South China Sea only $\left(22^{\circ} \mathrm{N}, 110^{\circ}-\right.$ $\left.120^{\circ} \mathrm{E}\right)$, i.e., (not shown here), HadGEM3's CON produces a strong monsoon bias with enhanced moisture flux toward China, resulting in an annual total that is $25 \%$ greater than observed estimates. This positive bias is not obvious when considering a wider domain covering both the South China Sea and the western Pacific, as shown in Fig. 5d. This is most 
likely due to HadGEM3's bias in simulating the positionparticularly the westward extension—of the western Pacific subtropical high, leading to a weaker southeasterly moisture flux from the western Pacific and thus cancelling out the strong bias over the South China Sea. FGOALS-f does not show such sensitivity to the choice of domain when calculating the annual southerly moisture flux associated with the EASM and produces accurate results when compared to observed estimates.

The responses of the EASM northward moisture flux in the experiments are quite consistent between the two models. Removing the TP and Himalaya in NoTP again yields a significant reduction in moisture flux in both models, albeit HadGEM3 shows a much larger reduction (75\%) compared to FGOALS-f (44\%). Despite the disagreement between the two models on the impact of the TP on summer rainfall over China, as shown in the previous section, similar changes in moisture flux are found in the HM-IPonly and HMonly experiments, which both lack the TP but retain the Himalaya. A reduced annual total moisture flux is found in both experiments $(-24 \%$ to $-33 \%$ in FGOALS-f, $-38 \%$ to $-42 \%$ in HadGEM3) compared to CON. Relatively little change is found in NoIP for both models compared to other experiments, suggesting that the remote IP plays little role in altering northward moisture fluxes toward China.

\subsection{Sensitivity experiments: changes in upper- tropospheric temperature and circulation}

\subsubsection{Large-scale view}

The previous section demonstrates that moisture flux can be used as a quantitative means of evaluating changes in monsoon strength and provides more consistent results in the two models compared to rainfall. Apart from rainfall and moisture transport, another crucial aspect of both the ISM and EASM is the meridional temperature gradient through the depth of the troposphere that maintains the cross-equatorial overturning circulation (e.g., Xavier et al., 2007). In this section, we examine the changes in mid-to-upper tropospheric temperature and the meridional temperature gradient in the Asian monsoon region across the sensitivity experiments from both models.

Figure 6 shows the changes in summer temperature averaged between 400 and $200 \mathrm{hPa}$ for all sensitivity experiments, alongside the upper-tropospheric circulation. Both models show a similar response but HadGEM3 generally shows larger changes compared to FGOALS. In NoTP (Figs. $6 \mathrm{a}$ and $\mathrm{b}$ ), both models show a drastic $3-5 \mathrm{~K}$ reduction in temperature associated with a cyclonic anomaly, indicating a weakened South Asian/Tibetan high compared to CON once elevated heating from the TP and Himalaya is removed. Also, HadGEM3 shows a larger reduction in temperature covering an extensive region from the Mediterranean to the coast of China, while in FGOALS the cooling signal is weaker and centered further to the west over the Hindu Kush region. In HM-IPonly (Figs. 6c and d), both models show weaker cooling of $2-4 \mathrm{~K}$ and a reduced cyclonic circula- tion anomaly compared to NoTP, demonstrating the crucial role played by the Himalaya in maintaining the South Asian high. HadGEM3 again shows stronger and more extensive cooling, while the changes in FGOALS are confined over the now-lowered TP. In NoIP (Figs. 6e-f), both models show 2-4 $\mathrm{K}$ cooling over the lowered IP and 1-2 K warming further downstream over the northern TP. In this particular experiment, the cooling over the IP is stronger in FGOALS compared to HadGEM3. Results from HMonly (Figs. $6 \mathrm{~g}$ and $\mathrm{h}$ ) are generally similar to those in NoIP, except that the warming over the northern TP is missing, while the southern TP in both models is affected by reduced temperature. Opposite to the results in NoIP, HadGEM3 shows a stronger cooling over the lowered IP in HMonly.

\subsubsection{Meridional temperature gradient index}

We next quantify the changes in meridional temperature gradient in the ISM region among the sensitivity experiments. Following Xavier et al. (2007), the gradient is defined using the mean temperature in the 400-200 hPa layer, averaged over two adjacent boxes at $15^{\circ} \mathrm{S}-5^{\circ} \mathrm{N}, 40^{\circ}-100^{\circ} \mathrm{E}$ and $5^{\circ}$ $35^{\circ} \mathrm{N}, 40^{\circ}-100^{\circ} \mathrm{E}$, respectively. The onset and withdrawal of the ISM are then defined as the times when the gradient becomes positive in spring and later becomes negative in autumn, respectively. The different biases in simulating the ISM from both models are also reflected in the results (Figs. $7 \mathrm{a}$ and $\mathrm{b}$ ). Consistent with the strong ISM bias, FGOALS's $\mathrm{CON}$ has a $0.5 \mathrm{~K}$ stronger gradient compared to reanalysis estimates. The peak gradient also shifts from mid-July to early July, while the onset and retreat timing of the ISM are captured accurately. In HadGEM3's CON, the temperature gradient during most of the year is $0.7 \mathrm{~K}$ weaker compared to observed estimates under the weak ISM bias. The monsoon duration is also shorter, with the onset delayed from mid-May to early June and an earlier retreat in late September.

Both models show a reduced meridional temperature gradient in NoTP. While FGOALS-f shows a $1.5 \mathrm{~K}$ reduction in the peak gradient during August, with little change in onset and retreat, HadGEM3 has a stronger reduction relative to its $\mathrm{CON}$, showing a reduction of more than $2 \mathrm{~K}$ in the peak gradient in August and a significantly shorter monsoon duration starting in July and retreating in early September. In HM-IPonly, the meridional temperature gradient in both models is more like CON relative to NoTP, with FGOALS-f and HadGEM3 showing a 0.7 to $0.9 \mathrm{~K}$ reduction in peak gradient, respectively, along with a delayed onset in HadGEM3. Removing the IP in NoIP has relatively little impact compared to other experiments, while in HMonly a larger reduction in peak temperature gradient ( $1 \mathrm{~K}$ in FGOALS-f, 1.25 $\mathrm{K}$ in HadGEM3) is found, with HadGEM3 again showing a delayed onset.

\section{Conclusion and discussion}

In this study we examine the impact of orography on the Asian summer monsoons by conducting various sensitivity 


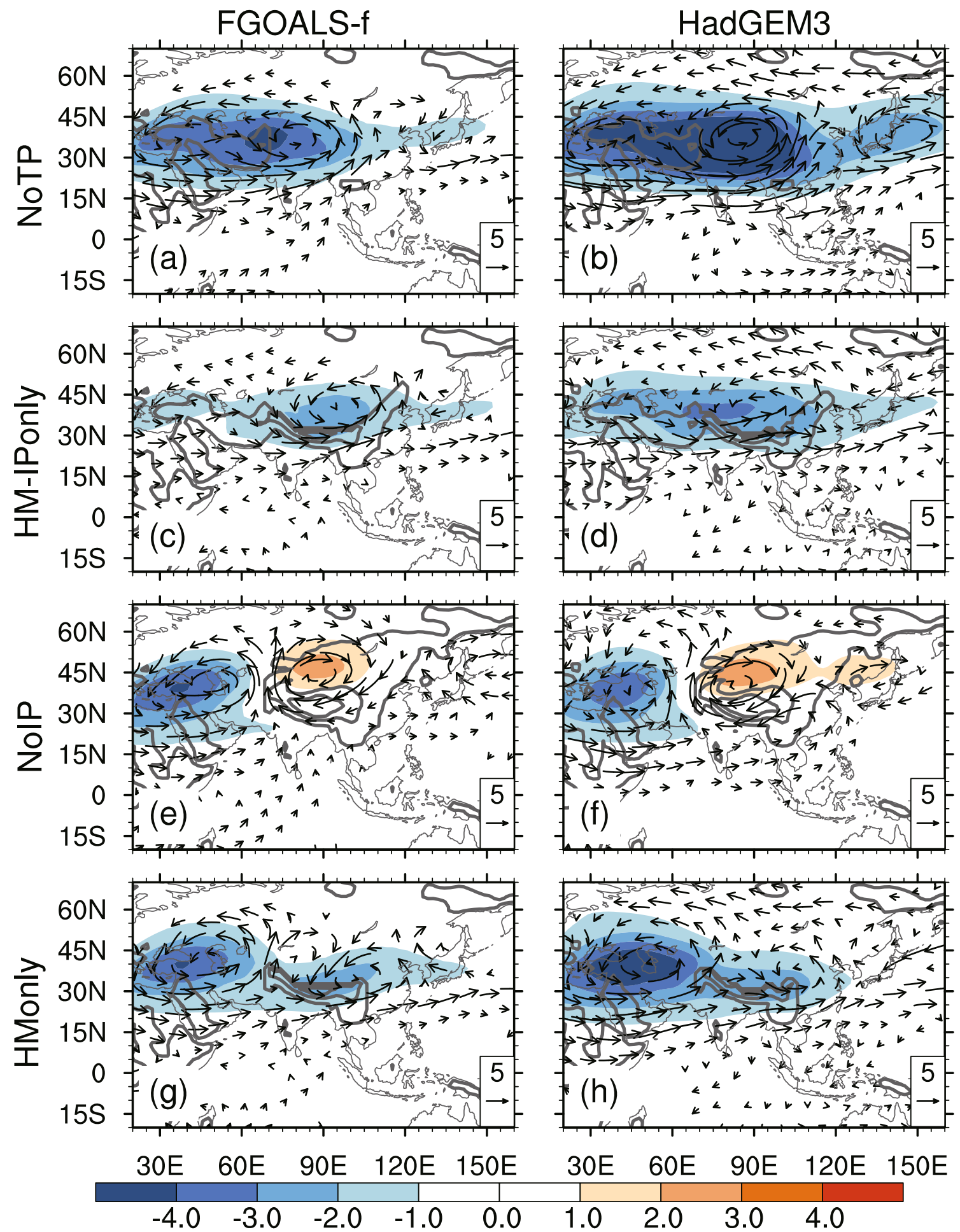

Fig. 6. As in Fig. 3 but for $200 \mathrm{hPa}$ wind (vectors; units: $\mathrm{m} \mathrm{s}^{-1}$ ) and 400-200 hPa average temperature (shading; units: K).

experiments using the UK Met Office's HadGEM3-GA6 and the IAP's FGOALS-f global climate models in atmosphereonly configurations. The sensitivity experiments are designed to isolate the combined impact of mechanical blocking and elevation of surface heating by lowering key terrain in Asia, including the TP, Himalaya and IP, to only $500 \mathrm{~m}$ above sea level. By running these experiments in global climate models that feature opposing biases in their simulation of the climatological mean of the Asian summer monsoon (strong ISM bias in FGOALS-f, weak ISM bias in HadGEM3), this study also highlights the model dependency of the results.

The responses of ISM circulation to changes in orography are largely consistent with previous studies. Without the TP and Himalaya, a much weaker summer monsoon circula- 
(a) FGOALS-f

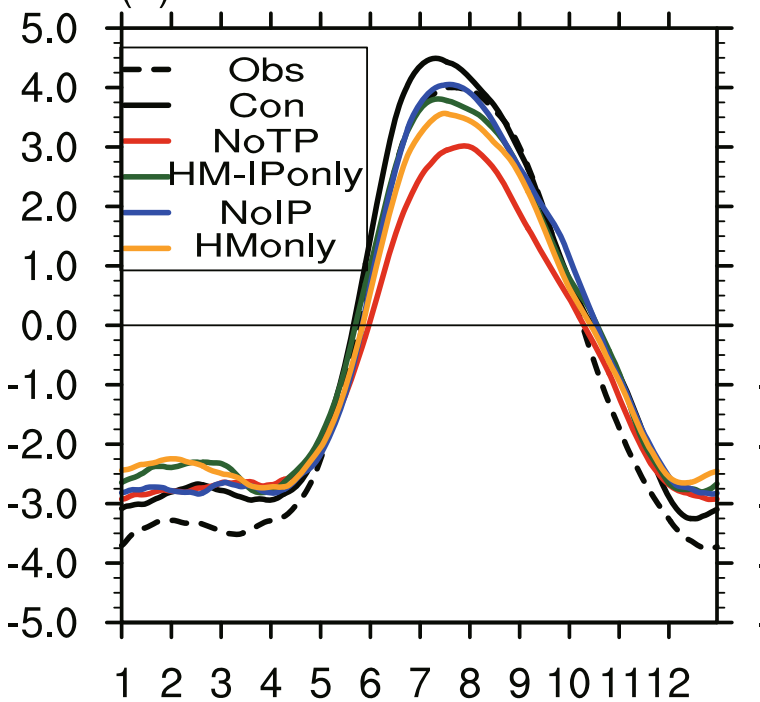

(b) HadGEM3

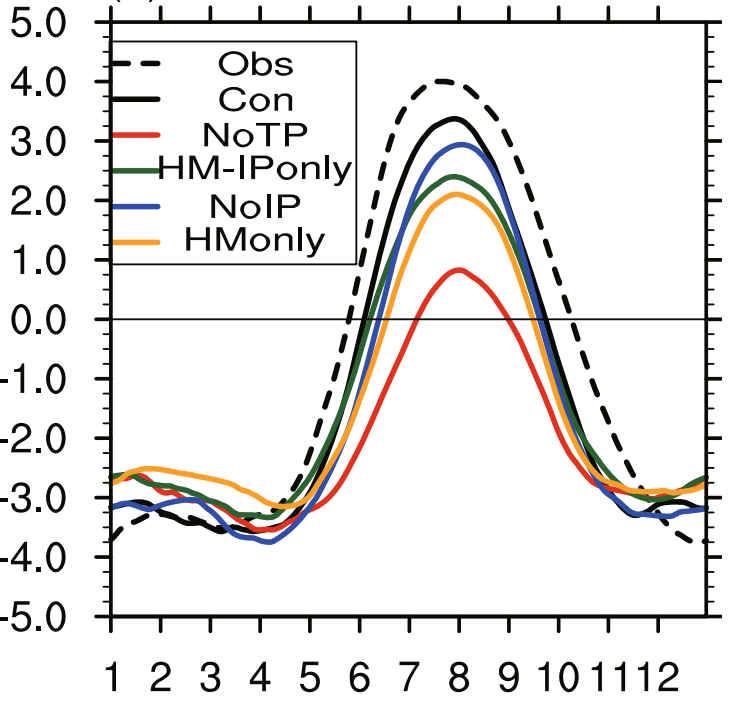

Fig. 7. 400-200 hPa averaged temperature difference (units: K) between a northern box $\left(5^{\circ}-35^{\circ} \mathrm{N}, 40^{\circ}-100^{\circ} \mathrm{E}\right)$ and a southern box $\left(15^{\circ} \mathrm{S}-5^{\circ} \mathrm{N}, 40^{\circ}-100^{\circ} \mathrm{E}\right)$ in observed estimates (dashed black line), (a) FGOALS-f and (b) HadGEM3.

tion at the $850 \mathrm{hPa}$ level is found in both models. By then replacing the Himalaya, the ISM improves greatly, with the circulation more consistent to CON. The IP also has a significant influence on the ISM circulation, particularly for the summer westerlies over the Arabian Sea.

Despite the consistent change in circulation across the sensitivity experiments in both models, the changes in rainfall over India are highly model dependent. Results from FGOALS-f are generally more like those in previous studies, showing reduced rainfall over India associated with a weakened ISM circulation in experiments that lack the Himalaya or IP. Meanwhile, rainfall changes in HadGEM3 seem, when viewed superficially, contradictory to the circulation response, with increased summer rainfall over India under a weakened ISM circulation. However, the local details of the patterns of change in moisture convergence are consistent with the rainfall responses in the models.

For the EASM, a weakened monsoon is found in both models when the TP and Himalaya are removed. Similar to the ISM results, the EASM is more consistent with CON in experiments that retain the Himalaya, even without the TP. However, the models disagree on the responses in summer rainfall over China. In FGOALS-f, the change in rainfall relative to $\mathrm{CON}$ is relatively small, even under a diminished EASM, when both the TP and Himalaya are lowered. Results from HadGEM3 show greater sensitivity to the presence of the TP, as reduced summer rainfall over China is found in all experiments that lack the TP, even when the Himalaya are retained and the EASM circulation is fairly consistent to CON. Although this study only uses two AGCMs, meaning the results presented here provide a somewhat limited view, the different rainfall response in both monsoon regions suggests that further investigation with a multi-model approach, as in the GMMIP-CMIP6-endorsed experiments, is urgently needed in order to clarify the impact of orographic forcing on the Asian monsoons.

The upper-tropospheric temperature in both models also shows different sensitivity to changes in elevation of surface sensible heating across the experiments. Overall, HadGEM3 is more sensitive to changes in elevation over the TP, with stronger and more extensive cooling in the mid-to-upper troposphere in all experiments that lower the TP. Compared to HadGEM3, FGOALS-f is less sensitive to the change in orography over the TP but shows a greater response when the IP is lowered. One of the most interesting differences between the FGOALS-f and HadGEM3 model responses occurs in the NoTP and HMonly experiments (Figs. 6a and b, 6g and h). In HadGEM3 there is a noticeable temperature reduction over the Japan region in response to removal of the TP, illustrating a clear downstream response. This is associated with a local cyclonic anomaly at upper levels, particularly in NoTP (Fig. 6b). Evidence of a baroclinic response is found in the lower troposphere (Fig. 3a), albeit with some vertical tilt. This underlines the potential for a remote influence on the East Asian region by orography around Tibet.

The impact of the IP on the ISM also requires further investigation. In NoIP, both models demonstrate similar weakening of summer westerlies over the northern Arabian Sea and reduced moisture flux toward India. Separate investigations (WTS2017) also have also shown lower equivalent potential temperature over the Arabian Sea and northern India associated with the southward movement of the dry continental airmass when the IP is lowered, therefore demonstrating the contribution of mechanical blocking from the IP in maintaining the humid nature of the monsoonal moisture flux. However, both models also show significant cooling in the mid-to-upper troposphere centered over the lowered IP, suggesting that elevated surface sensible heating from the IP strongly affects the tropospheric temperature in the region. Therefore, further investigation is needed to determine 
whether the weakening in summer westerlies and moisture flux are simply caused by the removal of mechanical blocking, or are a dynamical response to the change in thermal forcing.

The changes in meridional temperature gradient are also used to evaluate the strength of the ISM in the sensitivity experiments. Despite the opposing biases in CON compared to observed estimates, both models show similar changes in meridional temperature gradient. Removing both the TP and Himalaya leads to the largest reduction in peak temperature gradient in both models, while retaining the Himalaya produces results similar to CON. While the responses in peak temperature gradient are similar, HadGEM3 shows greater variation in the duration of the monsoon. In particular, in NoTP, the onset of the weakened ISM in HadGEM3 is delayed by more than a month, while FGOALS shows little-tono change in the monsoon onset or retreat relative to its CON. Therefore, even though the overall change in ISM (e.g., circulation, annual total moisture flux, peak temperature gradient) may be similar between both models, considerable differences exist in the more detailed aspects of the monsoon. Further investigation of the onset process is planned in a future study using suitable diagnostics, such as those presented in Wang and Lin (2002) and Parker et al. (2016).

Acknowledgements. This study was supported jointly by the UK-China Research and Innovation Partnership Fund through the Met Office Climate Science for Service Partnership (CSSP) China and the Major Research Plan of the National Natural Science Foundation of China (Grant Nos. 91637312 and 91437219).

Open Access This article is distributed under the terms of the Creative Commons Attribution License which permits any use, distribution, and reproduction in any medium, provided the original author(s) and the source are credited.

\section{REFERENCES}

Adler, R. F., and Coauthors, 2003: The version-2 global precipitation climatology project (GPCP) monthly precipitation analysis (1979-present). Journal of Hydrometeorology, 4(6), 1147-1167, https://doi.org/10.1175/1525-7541(2003) 004<1147:TVGPCP $>2.0$. CO;2.

Boos, W. R., and Z. M. Kuang, 2010: Dominant control of the South Asian monsoon by orographic insulation versus plateau heating. Nature, 463(7278), 218-222, https://doi.org/ 10.1038/nature08707.

Boos, W. R., and Z. M. Kuang, 2013: Sensitivity of the South Asian monsoon to elevated and non-elevated heating. Scientific Reports, 3, 1192, https://doi.org/10.1038/srep01192.

Bollasina, M. A., and Y. Ming, 2013: The general circulation model precipitation bias over the southwestern equatorial Indian Ocean and its implications for simulating the South Asian monsoon. Climate Dyn., 40(3-4), 823-838, https:// doi.org/10.1007/s00382-012-1347-7.

Clough, S. A., M. W. Shephard, E. J. Mlawer, J. S. Delamere, M. J. Iacono, K. Cady-Pereira, S. Boukabara, and P. D. Brown, 2005: Atmospheric radiative transfer modeling: A summary of the AER codes. Journal of Quantitative Spectroscopy and Radiative Transfer, 91, 233-244, https://doi.org/10.1016/ j.jqsrt.2004.05.058.

Dee, D., and Coauthors, 2011: The ERA-Interim reanalysis: Configuration and performance of the data assimilation system. Quart. J. Roy. Meteor. Soc., 137(656), 553-597, https:// doi.org/10.1002/qj.828.

Dong, G. T., H. Zhang, A. Moise, L. Hanson, P. Liang, and H. Ye, 2016: CMIP5 model-simulated onset, duration and intensity of the Asian summer monsoon in current and future climate. Climate Dyn., 46, 355-385, https://doi.org/10.1007/s00382015-2588-z.

Edwards, J. M. and A. Slingo, 1996: Studies with a flexible new radiation code. I: Choosing a configuration for a large-scale model. Quart. J. Roy. Meteor. Soc., 122, 689-719, https:// doi.org/10.1002/qj.49712253107.

Feng, J. M., T. Wei, W. J. Dong, Q. Z. Wu, and Y. L. Wang, 2014: CMIP5/AMIP GCM Simulations of East Asian Summer Monsoon. Adv. Atmos. Sci., 31, 836-850, https://doi.org/ 10.1007/s00376-013-3131-y.

Flohn, H., 1957: Large-scale aspects of the "summer monsoon" in South and East Asia. J. Meteor. Soc. Japan, 35A, 180-186, https://doi.org/10.2151/jmsj1923.35A.0_180.

Fritsch, J. M., and C. F. Chappell, 1980: Numerical prediction of convectively driven mesoscale pressure systems. Part I: Convective parameterization. J. Atmos. Sci., 37, 1722-1733, https://doi.org/10.1175/1520-0469(1980)037 $<1722$ :NPOCDM>2.0.CO;2.

Gates, W. L., and Coauthors, 1998: An overview of the results of the Atmospheric Model Intercomparison Project (AMIP I). Bull. Amer. Meteor. Soc., 80, 29-56, https://doi.org/10.1175/ 1520-0477(1999)080<0029:AOOTRO > 2.0.CO;2.

Gregory, D., and P. R. Rowntree, 1990: A mass flux convection scheme with representation of cloud ensemble characteristics and stability-dependent closure. Mon. Wea. Rev., 118, 1483-1506, https://doi.org/10.1175/1520-0493(1990) $118<1483$ :AMFCSW $>2.0 . C O ; 2$.

Harris, L. M., and S.-J. Lin, 2014: Global-to-regional nested grid climate simulations in the GFDL high resolution atmospheric model. J. Climate, 27, 4890-4910, https://doi.org/10.1175/ JCLI-D-13-00596.1.

Holtslag, A. A. M., and B. A. Boville, 1993: Local versus nonlocal boundary-layer diffusion in a Global Climate Model. J. Climate, 6, 1825-1842, https://doi.org/10.1175/1520-0442 (1993)006<1825:LVNBLD>2.0.CO;2.

Kitoh, A., H. Endo, K. K. Kumar, I. F. A. Cavalcanti, P. Goswami, and T. J. Zhou, 2013. Monsoons in a changing world: A regional perspective in a global context. J. Geophys. Res., 118(8), 3053-3065, https://doi.org/10.1002/jgrd.50258.

Li, C. F., and M. Yanai, 1996: The onset and interannual variability of the Asian summer monsoon in relation to land-sea thermal contrast. J. Climate, 9(2), 358-375, https://doi.org/10.1175/ 1520-0442(1996)009<0358:TOAIVO>2.0.CO;2.

Lin, S.-J., 2004: A "Vertically Lagrangian" finite-volume dynamical core for global models. Mon. Wea. Rev., 132, 22932307, https://doi.org/10.1175/1520-0493(2004)132<2293: AVLFDC $>2.0 . C O ; 2$.

Lock, A. P., A. R. Brown, M. R. Bush, G. M. Martin, and R. N. B. Smith, 2000: A new boundary layer mixing scheme. Part I: Scheme description and single-column model tests. Mon. Wea. Rev., 128, 3187-3199, https://doi.org/10.1175/15200493(2000)128<3187:ANBLMS>2.0.CO;2. 
Ma, D., W. Boos, and Z. M. Kuang, 2014: Effects of orography and surface heat fluxes on the South Asian summer monsoon. J. Climate, 27(17), 6647-6659, https://doi.org/10.1175/JCLID-14-00138.1.

Nordeng, T. E., 1994: Extended versions of the convective parameterization scheme at ECMWF and their impact on the mean and transient activity of the model in the tropics. ECMWF Technical Memorandum, 26.

Palmer, T. N., G. J. Shutts, and R. Swinbank, 1986: Alleviation of a systematic westerly bias in general circulation and numerical weather prediction models through an orographic gravity wave drag parametrization. Quart. J. Roy. Meteor. Soc., 112, 1001-1039.

Parker, D. J., P. Willetts, C. Birch, A. G. Turner, J. H. Marsham, C. M. Taylor, S. Kolusu, and G. M. Martin, 2016: The interaction of moist convection and mid-level dry air in the advance of the onset of the Indian monsoon. Quart. J. Roy. Meteor. Soc., 142(699), 2256-2272, https://doi.org/10.1002/qj.2815.

Putman, W. M., and S.-J. Lin, 2007: Finite-volume transport on various cubed-sphere grids. J. Comput. Phys., 227, 55-78, https://doi.org/10.1016/j.jcp.2007.07.022.

Scaife, A. A., N. Butchart, C. D. Warner, and R. Swinbank, 2002: Impact of a spectral gravity wave parameterization on the stratosphere in the Met Office Unified Model. $J$. Atmos. Sci., 59, 1473-1489, https://doi.org/10.1175/1520-0469 (2002) $059<1473:$ IOASGW > 2.0.CO; 2 .

Song, F. F., and T. J. Zhou, 2014. Interannual variability of East Asian summer monsoon simulated by CMIP3 and CMIP5 AGCMs: Skill dependence on Indian Ocean-western Pacific anticyclone teleconnection. J. Climate, 27(4), 1679-1697, https://doi.org/10.1175/JCLI-D-13-00248.1.

Sperber, K. R., H. Annamalai, I.-S. Kang, A. Kitoh, A. Moise, A. Turner, B. Wang, and T. Zhou, 2013: The Asian summer monsoon: An intercomparison of CMIP5 vs. CMIP3 simulations of the late 20th century. Climate Dyn., 41(9-10), 27112744, https://doi.org/10.1007/s00382-012-1607-6.

Tiedtke, M., 1989: A comprehensive mass flux scheme for cumulus parameterization in large-scale models. Mon. Wea. Rev., 117, 1779-1800, https://doi.org/10.1175/1520-0493(1989) $117<1779$ :ACMFSF $>2.0 . \mathrm{CO} ; 2$.

Walters, D., and Coauthors, 2017: The Met Office Unified Model global atmosphere 6.0/6.1 and JULES global land 6.0/6.1 configurations. Geoscientific Model Development, 10, 14871520, https://doi.org/10.5194/gmd-2016-194.

Wang, B., and H. Lin, 2002: Rainy season of the Asian-Pacific summer monsoon. J. Climate., 15(4), 386-398, https://doi. org/10.1175/1520-0442(2002)015<0386:RSOTAP>2.0.CO;2.

Wang, Z. Q., G. Li, and S. Yang, 2017: Origin of Indian summer monsoon rainfall biases in CMIP5 multimodel ensemble. Climate Dyn., https://doi.org/10.1007/s00382-017-3953-x.

Wilson, D. R., A. C. Bushell, A. M. Kerr-Munslow, J. D. Price, and C. J. Morcrette, 2008a: PC2: A prognostic cloud fraction and condensation scheme. I: Scheme description. Quart. J. Roy. Meteor. Soc., 134, 2093-2107, https://doi.org/10.1002/ qj.333.

Wilson, D. R., A. C. Bushell, A. M. Kerr-Munslow, J. D. Price, C. J. Morcrette, and A. Bodas-Salcedo, 2008b: PC2: A prognostic cloud fraction and condensation scheme. II: Climate model simulations. Quart. J. Roy. Meteor. Soc., 134, 21092125, https://doi.org/10.1002/qj.332.

Wood, N., and P. J. Mason, 1993: The pressure force induced by neutral, turbulent flow over hills. Quart. J. Roy. Meteor. Soc., 119, 1233-1267, https://doi.org/10.1002/qj.49711951402.

Wu, G. X., Y. M. Liu, B. He, Q. Bao, A. M. Duan, and F. F. Jin, 2012: Thermal controls on the Asian summer monsoon. Scientific Reports, 2, 404, https://doi.org/10.1038/srep00404.

Wu, G. X., and Coauthors, 2007: The influence of mechanical and thermal forcing by the Tibetan Plateau on Asian climate. Journal of Hydrometeorology, 8(4), 770-789, https://doi.org/ 10.1175/JHM609.1.

Xavier, P. K., C. Marzin, and B. N. Goswami, 2007: An objective definition of the Indian summer monsoon season and a new perspective on the ENSO-monsoon relationship. Quart. J. Roy. Meteor. Soc., 133(624), 749-764, https://doi.org/ 10.1002/qj.45.

Yanai, M., C. F. Li, and Z. S. Song, 1992: Seasonal heating of the Tibetan Plateau and its effects on the evolution of the Asian summer monsoon. J. Meteor. Soc. Japan, 70(1B), 319-351, https://doi.org/10.2151/jmsj1965.70.1B_319.

Ye, D. Z., 1981: Some characteristics of the summer circulation over the Qinghai-Xizang (Tibet) Plateau and its neighborhood. Bull. Amer. Meteor. Soc., 62, 14-19, https://doi.org/ 10.1175/1520-0477(1981)062<0014:SCOTSC $>2.0 . C O ; 2$.

Yu, H.-Y., Q. Bao, L.-J. Zhou, X.C. Wang, and Y.-M. Liu, 2014: Sensitivity of precipitation in aqua-planet experiments with an AGCM. Atmospheric and Oceanic Science Letters, 7, 1-6, https://doi.org/10.3878/j.issn.1674-2834.13.0033.

Zhou, L. J., and Coauthors, 2015: Global energy and water balance: characteristics from finite-volume atmospheric model of the IAP/LASG (FAMIL1). Journal of Advances in Modeling Earth Systems, 7, 1-20, https://doi.org/10.1002/2014 MS000349.

Zhou, L.-J., Y.-M. Liu, Q. Bao, H.-Y. Yu, and G.-X. Wu, 2012: Computational performance of the high-resolution atmospheric model FAMIL. Atmospheric and Oceanic Science Letters, 5, 355-359, https://doi.org/10.1080/16742834.2012. 11447024.

Zhou, T. J., and Coauthors, 2016: GMMIP (v1.0) contribution to CMIP6: Global monsoons model inter-comparison project. Geoscientific Model Development, 9(10), 3589-3604, https:// doi.org/10.5194/gmd-9-3589-2016. 